\title{
Profiling of student-athletes using protective behavioral strategies and alcohol use based on cluster analysis assignment
}

\author{
Lindsey Sanders ${ }^{1}$, William Dudley², \\ Jeffrey Milroy², and David Wyrick ${ }^{2}$
}

\begin{abstract}
An estimated 2 in 3 college students report consuming alcohol in the past month and $44 \%$ of students report engaging in high risk or heavy episodic drinking at least once in the previous 2 weeks. Despite evidence suggesting that participation in sports may be a protective factor for the use of alcohol, recent data from the National Collegiate Athletic Association (NCAA), finds that $77 \%$ college student-athletes report use. Though overall prevalence rates of alcohol consumption are similar among college student-athletes and non-athletes, student-athletes are more likely to engage in binge or high-risk drinking as compared to their non-athlete peers. An overwhelming majority of studies found that protective behavioral strategy (PBS) use was associated with less drinking and alcoholrelated problems. There are sport-related factors that have been assessed to determine their association with use of alcohol-related PBS. With known factors in mind, prevention programs are typically developed to effect distal outcomes by way of these, more proximal, intermediate constructs that are thought to be related to the health problem of interest. The purpose of the current study was to examine the structural features that influence whether a given student-athlete will be categorized into one of three groups; a) high-risk drinking behaviors, b) moderate risk drinking behaviors, or c) low risk drinking behaviors.
\end{abstract}

Keywords: student-athletes; high-risk alcohol use; protective behavioral strategies; NCAA

1. Graduate Student, University of North Carolina at Greensboro, Institute to Promote Athlete Health \& Wellness

2. University of North Carolina at Greensboro, Department of Public Health Education

Address for correspondence: ldsander@uncg.edu

Date of first (online) publication: 10th October 2019 


\section{Introduction}

Research suggests that almost 60 percent of college students drink alcohol during the academic year, (Terlecki, Buckner, Larimer, \& Copeland, 2015; SAMHSA, 2014; Johnston, O'Malley, Bachman, \& Schulenberg, 2010) and nearly 44 percent of college students report engaging in high risk or heavy episodic drinking at least once during that same timeframe (Linden-Carmichael, Vasilenko, Lanza, $\&$ Maggs, 2017; Jackson, 2008; Wechsler \& Nelson, 2008). Despite evidence suggesting that participation in sports may be a protective factor for the use of alcohol (Martens, 2017; Lisha \& Sussman, 2010; Naylor, Gardner, \& Zaichkowsky, 2001), recent data from the National Collegiate Athletic Association (NCAA), finds that $77 \%$ college student-athletes report use (NCAA, 2018). Though overall prevalence rates of alcohol consumption are similar among college student-athletes and non-athletes, student-athletes are more likely to engage in binge or high-risk drinking as compared to their non-athlete peers (NCAA, 2018; Green, Hartman, \& Nelson, 2014; Kwan, Bobko, Faulkner, Donnelly, \& Cairney, 2014).

Alcohol Myopia Theory suggests that many of alcohol's social and stressreducing effects, which may underlie its addictive capacity, are explained as a consequence of alcohol's narrowing of perceptual and cognitive functioning (Lewis, Rees, Logan, Kaysen, \& Kilmer, 2010). Alcohol has been implicated as a risk factor for negative consequences; however, various studies demonstrate that use of alcohol-related protective behavioral strategies (PBS) could assist in the reduction of risks while drinking (Samuolis, Loser, \& Tyrrell, 2018; Lewis, et al., 2010). Alcohol-related PBS are cognitive-behavioral strategies used to limit alcohol consumption and/or minimize negative consequences (Lewis, et al., 2010). These strategies include spacing drinks, alternating alcoholic drinks with non-alcoholic beverages, setting a limit on consumption, or finding alternative activities that do not include alcohol. Many of the negative consequences experienced by college students who drink include physical, cognitive, and social impacts. However, these effects are exacerbated by the performance demands for student-athletes, that non-athelete students do not experience. (Denny $\&$ Steiner, 2009). Physical and cognitive side effects such as dehydration, increased blood pressure, and difficulty concentrating can result in increased risk for injury, and longer recovery time for student-athletes (Shirreffs \& Maughan, 2006; O'Brien \& Lyons, 2000). In addition, risky behaviors associated with heavy alcohol consumption (e.g., underage drinking, driving under the influence, acts of vandalism, etc.) can have legal ramifications for college student-athletes and could be challenging for their eligibility to continue preforming in their sport. Thus, addressing high risk alcohol use and minimizing associated negative consequences among student-athletes is of central importance for professionals working in college sports settings.

In an extensive review of 62 studies conducted by Pearson (2013), a majority of studies found that PBS use was associated with less drinking therefore producing 
less alcohol-related problems (Voss, Soltis, Dennhardt, \& Martens, 2018). Some sport-related factors have been assessed to determine their association with use of alcohol-related PBS. For example, there are significant gender and ethnic differences in alcohol consumption as well as gender differences in use of PBS (Longo, Martin, Zamboanga, Milroy, \& Wyrick, 2018). Further, within-group gender differences for alcohol use and PBS are present for White and Hispanic student-athletes, but not for Black student-athletes. Research suggests that female student-athletes tend to implement protective behaviors more often and more effectively than males (LaBrie, Lac, Kenney, \& Mirza, 2011; Walters, Roudsari, Vader, \& Harris, 2007; Haines et al., 2006; Benton et al., 2004; Delva et al., 2004). Additionally, some support exists for racial differences as a predictor of alcohol use, suggesting that Whites are more likely to be heavy drinkers than their non-White peers (Brooks-Russell, Simons-Morton, Haynie, Farhat, \& Wang, 2014; Finlay, White, Mun, Cronley, \& Lee, 2012; Paschall \& Flewelling, 2002; Brown, Parks, Zimmerman, \& Phillips, 2001; Bradizza, Reifman, \& Barnes, 1999). Conversely, it appears that there is little correlation between sport type (i.e., contact vs noncontact) and use of PBS. (Autti, Sipila, Autti, \& Salonen, 1997).

Interventions aimed specifically at collegiate student-athletes have been successful at changing alcohol-related norms, expectancies, and intentions (Fearnow-Kenney, Wyrick, Milroy, Reifsteck, Kelly, Day, 2016). Essential to these interventions is the identification of risk and protective factors related to the targeted behavior change. With known factors in mind, prevention programs are typically developed to effect distal outcomes by way of these, more proximal, intermediate constructs that are thought to be related to the health problem of interest (MacKinnon, 1994). A prevention program is thus, designed to produce a change in a set of theory-informed mediators, and by doing so, is expected to produce change in the outcome (e.g., prevent, delay, or reduce the prevalence of the outcome). Theories of health behavior are typically used to guide the selection of mediators to be targeted in a prevention program. In addition to directly targeting individuals' intentions to limit alcohol consumption at heavy or extreme levels, cultivating intentions to prevent harm resulting from high-risk alcohol use may be an effective strategy for ameliorating risky alcohol-related behavior (Gastil, 2000). Behavioral intentions are in turn predictive of engaging in or avoiding substance use and its related consequences.

The purpose of the current study was to examine the structural features that influence whether a given student-athlete will be categorized into one of three groups; a) high-risk drinking behaviors, b) moderate risk drinking behaviors, or c) low risk drinking behaviors. Consistent with established research, higher intentions to drink are expected to be predictive of cluster membership. Cluster analysis is a statistical tool used to classify objects into groups, such that the objects belonging to each group are more similar to each other and rather different from objects belonging to other groups. The main benefit of cluster analysis is that 
it allows researchers to group similar data together. Grouping similar data can help identify patterns between data elements, reveal associations between data objects, helps to outline structure which might not have been apparent previously, and gives much sense and meaning to the data when discovered. Once a clear structure emerges, it allows for data-driven decisions. A better understanding of how cluster membership may predict the relationship between drinking motives and demographic characteristics, and within subgroups of students, is valuable to informing alcohol prevention initiatives targeting at-risk college student-athletes.

A central goal of this study is to shed light on the potential efficacy of a webbased intervention aimed at promoting the use of protective behavioral strategies.

\section{Participants}

Table 1

\begin{tabular}{llcc}
\hline & & Frequency & Percent \\
\hline Gender & Male & 1321 & 46.0 \\
& Female & 1249 & 43.5 \\
\hline Year in school & First-year & 2509 & 87.4 \\
& Second year & 123 & 4.3 \\
& Third year & 180 & 6.3 \\
& Fourth year & 37 & 1.3 \\
\hline \multirow{2}{*}{ Age } & 18 years & 2003 & 70.0 \\
& +18 years & 858 & 30.0 \\
\hline \multirow{2}{*}{ Contact Sports } & White & 2329 & 72.9 \\
& Non-White & 473 & 14.8 \\
\hline
\end{tabular}

Participants were NCAA Division II freshman and transfer student-athletes competing in the United States. The sample was limited to Division II studentathletes because there was an NCAA initiative focused on alcohol and other drug prevention for Division II student-athletes at the time of recruitment. Freshman and transfer student-athletes were selected as the focus of this study because students in their first year of college are more likely to engage in risky behaviors such as increased patterns of alcohol use (National Institute on Alcohol Abuse and Alcoholism, 2015). In addition, first-year student-athletes are less likely than veteran student-athletes to have been previously exposed to sport-related drug and alcohol prevention efforts due to limited potential exposure time as a student- 
athlete (NCAA, 2014). Thus, limiting the sample minimizes confounding of current exposure-outcome associations by previous exposure-outcome associations. Table 1 provide descriptive statistics for participant gender, race, and sport type.

Data from 2,871 student-athletes who completed a web-based survey are included in this study. For this study, we investigated characteristics of participant constructs including gender, year in school, age, race, and participation on contact versus noncontact sports. The frequencies are reported in Table 1.

\section{Measures}

Demographic questions were used to gather information regarding gender, age, ethnicity, and whether the sport they played is considered contact or non-contact, by NCAA standards. The primary outcome variables in this study are social norms, negative alcohol and marijuana expectancies, intentions to use harm prevention strategies, and knowledge about alcohol and other drugs.

Table 2

\begin{tabular}{ll}
\hline Contact Sports & Non-Contact Sports \\
\hline Baseball & Bowling \\
Basketball & Cross Country \\
Boxing & Golf \\
Fencing & Rifle \\
Field Hockey & Rowing \\
Football & Tennis \\
Gymnastics & Track \& Field \\
Ice Hockey & \\
Lacrosse & \\
Skiing & \\
Soccer & \\
Softball & \\
Swimming \& Diving & \\
Volleyball & \\
Water Polo & \\
Wrestling & \\
\hline
\end{tabular}

\section{Descriptive norms}

Descriptive norms were assessed using a one-item measure of participants' ratings for perceived prevalence of college student-athlete binge drinking (i.e., 'Overall, what 
percentage of collegiate student-athletes consumed five or more drinks in a row on at least one occasion in the last two weeks?). Possible options include an 11-point scale ranging from $0 \%$ to $91-100 \%$.

\section{The Negative Alcohol Expectancies}

The Negative Alcohol Expectancies subscale included 13 items that asked studentathletes on a 4 -point shale $(1=$ very unlikely, $4=$ very likely $)$ the likelihood of a list of potential consequences that might occur to them personally if they were to drink 5 or more whole drinks of an alcoholic beverage 2 to 3 times per week. Items included performance-related effects (e.g., reduced lean muscle mass, decrease in strength and performance), as well as general alcohol effects adapted from the Alcohol Expectancy Questionnaire (AEQ: Brown, Christiansen, \& Goldman, 1987; e.g., have a memory loss, get nauseated or vomit). The reliability for this measure was assessed in the current sample and demonstrated excellent consistency $(\alpha=.928)$.

\section{The Negative Marijuana Expectancies}

The Negative Marijuana Expectancies subscale included 12 items that asked studentathletes to rate on a 4 -point scale ( $1=$ very unlikely, $4=$ very likely) the likelihood of a list of potential consequences that might occur to them personally if they were to use marijuana or hashish once or twice per week. Items included performancerelated effects (e.g., reduced motivation to perform, reduced endurance because of limited VO2 max or aerobic capacity), as well as general marijuana effects (difficulty concentrating, do something you later regretted). The reliability for this measure was assessed in the current sample and demonstrated excellent consistency $(\alpha=.960)$.

\section{Intentions to Use Harm Prevention Strategies}

Intentions to Use Harm Prevention Strategies were assessed with the questions, 'How likely do you think it is that you will do the following in the next 30 days?' Responses to the 16-item measure was on a 5-point scale ( 1 = I definitely won't do this, 5 = I definitely will do this). Sample items include 'use a designated driver', 'alternate alcoholic and non-alcoholic drinks', 'use marijuana more than once in a week', and 'refuse an offer to use marijuana'. The reliability for this measure was assessed in the current sample and demonstrated acceptable consistency $(\alpha=.735)$. 


\section{Procedure}

Based on existing research highlighting the important influence of social norms, expectancies, and intentions on alcohol use and related consequences, an internetbased alcohol prevention program for college student-athletes, called myPlaybook, was developed. There are multiple advantages to internet-based behavioral interventions, including their broad reach, self-paced and interactive format, demonstrated success, and their cost-effectiveness as compared to facilitator-led interventions (Carey et al., 2009; Elliott et al., 2008; Hustad et al., 2010; Rooke et al., 2010). The flexibility they offer is particularly attractive for use with studentathletes who have demanding schedules (Brenner \& Swanik, 2007; Denny \& Steiner, 2009; Venne et al., 2006).

During the middle of the spring semester all NCAA Division II-affiliated colleges and universities at that time $(\mathrm{N}=296)$ received an emailed invitation from an NCAA representative to participate in a study of the myPlaybook program in the subsequent fall semester. The fall semester was selected for implementation because it is an optimal time to deliver alcohol and other drug prevention programming to student-athletes who are new to the university (i.e., freshman and transfer) (Fearnow-Kenney, Wyrick, Milroy, Reifsteck, Kelly, \& Day, 2016). Ninety-two institutions responded to this call and expressed interest in participating in the study. Administration turnover and other logistical issues (e.g., semester schedules) forced some schools to drop out before the start of the study leaving 60 schools who participated in the study. One athletic department administrator from each participating school served as a liaison for the study and participated in a 1-hr webinar training on the myPlaybook program and study protocol during the summer preceding the fall implementation.

At the beginning of the fall semester, freshman and transfer student-athletes from each participating school received an e-mail that included information about the study, instructions on how to access their myPlaybook account, and a link to the web-based pretest survey that was administered via SurveyMonkey. Of the 4,974 freshmen and transfer student-athletes who received the invitation to participate, 2,871 completed the pretest survey (58\% response rate). Among the pretest respondents, $47 \%$ ultimately completed the posttest, for a final sample of $n=1,356$. All participants completed the pretest during a 2-week window at the beginning of the fall semester. Pretest data were used to stratify schools on important demographic and outcome variables (e.g., gender, ethnicity, past 30 day alcohol and other drug use). Schools within each strata were then randomized to the treatment or delayed-treatment control group. This procedure resulted in 30 schools in each of the treatment $(n=1,527)$ and control $(n=1,344)$ groups. Participants in the treatment group completed the myPlaybook program during a 2-week implementation window, and then completed the posttest survey (final $\mathrm{n}=647$ ) within one week following the close of the implementation window. Participants 
from schools in the control group completed the posttest survey (final $n=709$ ) during the same one-week window as the treatment group and were then offered the opportunity to complete the myPlaybook program. The time between the pretest and posttest survey was an average of 47.63 days (mode $=56$ days).

\section{Data analysis}

All analyses were completed with SPSS ${ }^{\circledR}$ version 25.0 (SPSS Inc., Chicago, IL). Descriptive statistics and frequency distributions were generated to examine sample characteristics which are reported in table 1 . Cluster analyses were completed to identify mutually exclusive subgroups of student-athletes based on their responses on the intentions inventory. Ward's (1963) minimum-variance method was used for cluster extraction because it is used most frequently in research and performs the best at population recovery of clusters (Husic, McKiernan, Wayment-Steele, Sultan, \& Pande, 2018; Finch, 2005; Romesburg, 2004). Cluster solutions ranging from two through six were examined for interpretability. The decision about which solution to retain (class enumeration) employed the Calinski and Harabasz index (Milligan \& Cooper, 1985) which has been shown to be a highly reliable cluster validation index (Arbelaitz, Gurrutxaga, Muguerza, Pérez, \& Perona, 2013). A second consideration in class enumeration was the interpretability of the solution (Masyn, 2013). The Calinski and Harabasz index indicated choosing either a two or three class solution. We found that the three-class solution which included 2,521 of the 2,601 participants entered the analysis provided a more useful model for our study and we retained that solution for the analyses reported below.

Following the identification of mutually exclusive clusters using the Ward's method, we explored demographic differences across the three clusters. First, we employed bivariate analysis using the Cross-tab analysis with the chi-squared statistical test to examine the association between gender race and contact versus noncontact and cluster assignment. Second, we employed a multivariate approach in which we use the multinomial logistic regression model with cluster assignment as the dependent variable and explored the predictive value of gender race and contact versus no contact. In both of these analyses we employed list-wise deletion so that the sample being analyzed in the bivariate fashion would be the same as the sample employed in the multinomial logistic regression modeling. 


\section{Results}

The cluster analysis results are provided in figure 1 which shows the profile of risk and protective factors across three clusters which we identify as 'low risk', 'moderate risk', and 'high risk'.

We first describe the characteristics of the three clusters as shown in figure 1. Then we detail the results of the bivariate analysis using the Cross tab and chi-square statistic. Finally, we examine the results of the multinomial logistic regression model

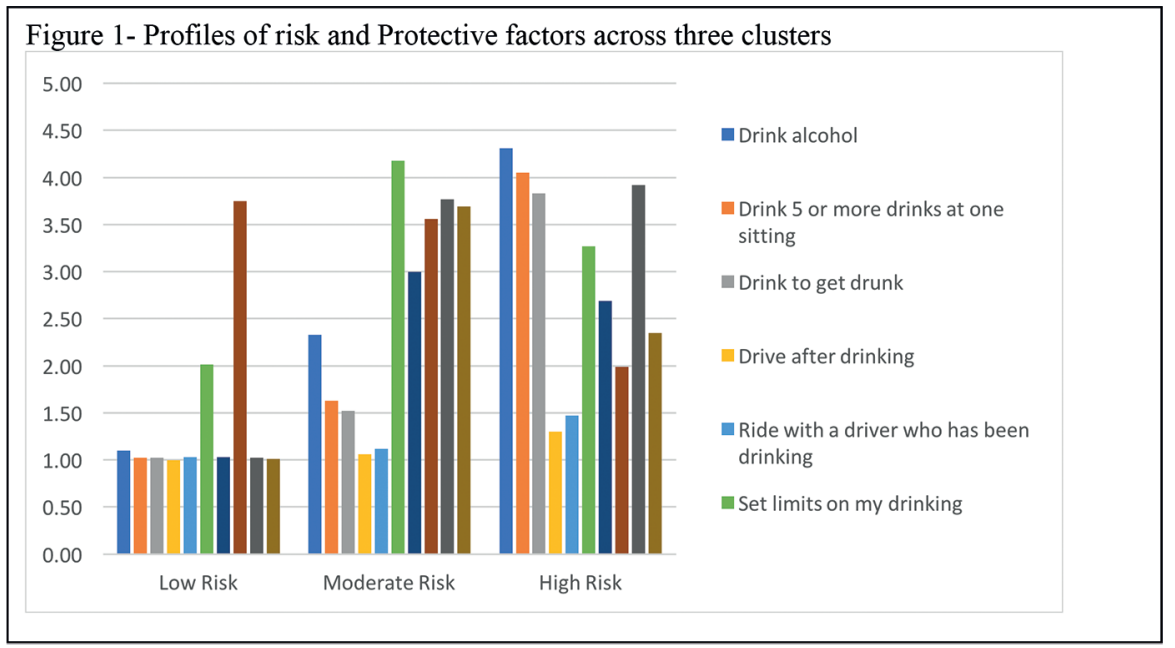

\section{Cluster 1 Low Risk ( $=602,23.88 \%)$}

As can be seen in Figure 1, these participants indicated a low level of intention to drink, and also reported low levels of protective factors. The salient features of this cluster were the high levels of intention to set limits on drinking and intentions to avoid drinking games. Other protective factors such as intentions to pace drinks to one drink or fewer per hour or alternate alcoholic drinks with non-alcoholic drinks were low, because these participants reported low intentions to drink alcohol or get drunk.

\section{Cluster 2 Moderate Risk ( $=1393,55.26 \%)$}

This is the largest of the three groups and captures moderate levels of intention to drink alcohol or other risky drinking behaviors such as drinking 5 or more drinks at one setting or driving after drinking. Importantly however, participants in this 
group reported high levels across all protective factors, such as setting limits on their drinking and intentions to pace drinks to one or fewer an hour.

\section{Cluster 3 High Risk (N = 526, 20.86\%)}

Also illustrated in Figure 1, these participants indicated a high level of drinking with salient factors of highest intention to drink alcohol, intentions to drink 5 or more drinks at one setting, and intentions to drink to get drunk. Other risk factors such as intentions to drive after drinking and intentions to ride with a driver who has been drinking were also present, but at lower levels. In addition to high level of drinking behaviors, this group also reported moderate levels of protective factors that could reduce the deleterious effects of drinking such as intention to alternate alcoholic and non-alcoholic drinks, and to eat before and during drinking. Clusters 1, 2, and 3 appeared similar in intentions to drive after drinking or ride with a driver who has been drinking. However, these clusters appear to differ in relation to their risk and protective factors.

\section{Bivariate association of demographics in cluster membership}

As noted in Table 3, there were significant associations between selected demographics and cluster membership. The Chi Square tests are all quite robust, with $\mathrm{P}$ values all below .001. It is important to note that the nature of these associations is that females, blacks, and non-contact sport players are more conservative with higher percent membership in low and moderate risk clusters.

\section{Multinomial Log Regression}

The bivariate associations reported above were expanded by employing a multivariable multinomial logistic regression model in which cluster membership was the dependent variable and factors included the binary variables reported above entered in a single block (Gender, Race, and Contact). Main effects and interactions were examined; however, only Main effects are reported below because no interactions attained statistical significance. The results of the regression are provided in table 4. 


\begin{tabular}{|c|c|c|c|c|c|c|c|c|c|c|c|c|c|c|c|}
\hline & 氶 & & $\begin{array}{l}\infty \\
\infty \\
0\end{array}$ & 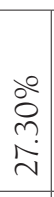 & & & $\begin{array}{c}\stackrel{a}{+} \\
m \\
-\end{array}$ & $\begin{array}{l}\circ \\
\text { ì } \\
\text { in } \\
\text { in }\end{array}$ & & & 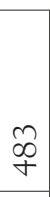 & $\begin{array}{c}\stackrel{0}{0} \\
\stackrel{1}{1} \\
\stackrel{2}{2}\end{array}$ & & $\begin{array}{l}\bar{\sim} \\
\tilde{\sim}\end{array}$ & \\
\hline \multirow{4}{*}{$\begin{array}{l}5 \\
\hat{0} \\
\tilde{0} \\
\tilde{0} \\
0 \\
0\end{array}$} & $\underset{ \pm}{ \pm}$ & & $\begin{array}{c}\stackrel{\bullet}{+} \\
\stackrel{+}{*} \\
\end{array}$ & 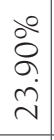 & $\begin{array}{l}\hat{i} \\
\hat{i}\end{array}$ & & $\begin{array}{l}q \\
a \\
a\end{array}$ & $\begin{array}{l}\text { o̊ } \\
0 \\
m \\
\hat{n} \\
n\end{array}$ & $\begin{array}{r}-1 \\
0 \\
0\end{array}$ & & ஜ̊ & $\begin{array}{l}\text { ôे } \\
\infty \\
i \\
i \\
\text {. }\end{array}$ & $\ddot{n}$ & $\begin{array}{l}\infty \\
\stackrel{\infty}{=}\end{array}$ & $\begin{array}{l}0 \\
f \\
0 \\
0\end{array}$ \\
\hline & Oे & & 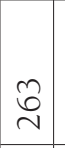 & $\begin{array}{l}\stackrel{0}{0} \\
\stackrel{n}{1} \\
n\end{array}$ & $\stackrel{m}{t}$ & & $\begin{array}{l}8 \\
\text { \& }\end{array}$ & $\begin{array}{l}80 \\
8 \\
\dot{0} \\
\dot{1} \\
i n\end{array}$ & $\stackrel{\sim}{0}$ & & $\stackrel{\infty}{\uparrow}$ & $\left|\begin{array}{c}0 \\
0 \\
0 \\
0 \\
-\end{array}\right|$ & $\begin{array}{l}\vec{p} \\
\ddot{i}\end{array}$ & $\vec{I}$ & $\stackrel{d}{4}$ \\
\hline & & & & & & & & & & & & & & & \\
\hline & $\begin{array}{l}\vec{\sigma} \\
0 \\
0 \\
0\end{array}$ & & $\begin{array}{l}\infty \\
\infty \\
0\end{array}$ & 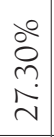 & & & $\begin{array}{l}\mathfrak{q} \\
\stackrel{f}{-}\end{array}$ & $\begin{array}{l}\text { ò } \\
0 \\
n \\
n \\
n\end{array}$ & & & @o & 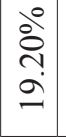 & & $\begin{array}{l}\overrightarrow{\widetilde{N}} \\
\overrightarrow{\mathrm{v}}\end{array}$ & \\
\hline & 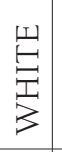 & & 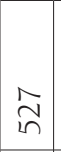 & $\begin{array}{l}\text { ○े } \\
\circ \\
\stackrel{1}{1} \\
\end{array}$ & $\frac{\sigma}{-1}$ & & \begin{tabular}{l}
$\infty$ \\
\multirow{J}{J}{} \\
$=$
\end{tabular} & $\begin{array}{l}a \\
0 \\
0 \\
\dot{1} \\
\text { in }\end{array}$ & $\overrightarrow{0}$ & & $\frac{+}{2}$ & 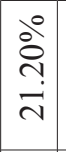 & $\vec{i}$ & 官 & $\begin{array}{l}2 \\
0 \\
\infty \\
\infty \\
\infty \\
\dot{\sigma}\end{array}$ \\
\hline & 岂 & & $\underset{\sigma}{\widetilde{\sigma}}$ & $\begin{array}{c}\dot{o} \\
\text { o } \\
\infty \\
\infty \\
m\end{array}$ & $\begin{array}{l}\stackrel{0}{ } \\
\stackrel{0}{ } \\
\stackrel{+}{*}\end{array}$ & & $\overrightarrow{\widetilde{N}}$ & $\begin{array}{l}\text { o̊ } \\
\text { o } \\
\dot{1} \\
i\end{array}$ & $\begin{array}{l}\text { o̊ } \\
8 \\
0 \\
\dot{1} \\
r\end{array}$ & & શे & 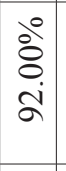 & $\begin{array}{l}\stackrel{0}{ } \\
\text { †े } \\
+1\end{array}$ & 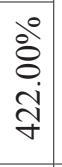 & $\widehat{d}$ \\
\hline & & & & & & & & & & & & & & & \\
\hline & $\begin{array}{c}\vec{\sigma} \\
0 \\
0 \\
0\end{array}$ & & $\begin{array}{l}\infty \\
\infty \\
0\end{array}$ & 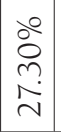 & & & 导 & $\begin{array}{l}80 \\
0 \\
n \\
i n \\
i n\end{array}$ & & & $\begin{array}{c}m \\
\dot{\infty} \\
\dot{\alpha}\end{array}$ & $\begin{array}{l}\stackrel{\circ}{0} \\
\text { 1’ } \\
\underline{-}\end{array}$ & & $\begin{array}{l}\overrightarrow{\widetilde{N}} \\
\vec{\sim}\end{array}$ & $\overline{8}$ \\
\hline \multirow{3}{*}{$\begin{array}{l}\overrightarrow{\tilde{z}} \\
\overrightarrow{\tilde{J}} \\
\mathbb{U}\end{array}$} & 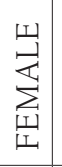 & & $\stackrel{m}{m}$ & 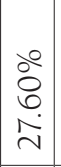 & $\stackrel{1}{0}$ & & $\begin{array}{l}0 \\
1 \\
1\end{array}$ & $\begin{array}{c}\circ 0 \\
\text { o } \\
+ \\
\dot{0}\end{array}$ & $\stackrel{\infty}{m}$ & & $\stackrel{m}{=}$ & $\mid \begin{array}{c}0 \\
\text { oे } \\
= \\
=\end{array}$ & $\begin{array}{l}n \\
0 \\
i \\
1\end{array}$ & $\underset{\Xi}{\stackrel{\Xi}{二}}$ & $\begin{array}{l}2 \\
\infty \\
\infty \\
8 \\
\stackrel{0}{0} \\
\|\end{array}$ \\
\hline & $\underset{\Sigma}{\stackrel{山}{\rightleftarrows}}$ & & 点 & 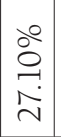 & $\begin{array}{l}2 \\
0 \\
1 \\
1\end{array}$ & & $\begin{array}{l}0 \\
0 \\
0\end{array}$ & $\mid \begin{array}{c}80 \\
0 \\
0 \\
0 \\
0 \\
+\end{array}$ & $\begin{array}{l}\stackrel{0}{r} \\
\stackrel{r}{1}\end{array}$ & & 吊 & $\left|\begin{array}{c}0 \\
0 \\
0 \\
0 \\
0\end{array}\right|$ & ?ु. & $\begin{array}{l}\hat{D} \\
-\end{array}$ & $\stackrel{d}{4}$ \\
\hline & & 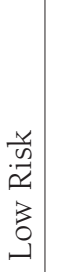 & $\begin{array}{l}\vec{\Xi} \\
\tilde{\Xi} \\
\mid\end{array}$ & 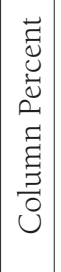 & 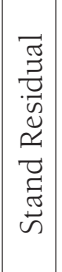 & 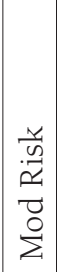 & $\begin{array}{l}\vec{\Xi} \\
\vec{\Xi} \\
0\end{array}$ & 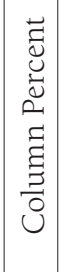 & 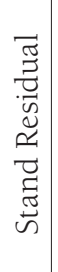 & 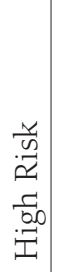 & $\begin{array}{c} \\
\vec{\Xi} \\
ن\end{array}$ & $\mid \begin{array}{c}\overrightarrow{0} \\
0 \\
0 \\
0 \\
2 \\
\vdots \\
\vdots \\
0 \\
0\end{array}$ & 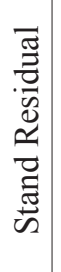 & $\vec{\Xi}$ & \\
\hline
\end{tabular}


Table 4. Results of the multivariate multinomial logistic regression

\begin{tabular}{|l|l|l|l|l|l|l|l|}
\hline & & & & & & \multicolumn{2}{|c|}{$\begin{array}{c}\text { 95\% Confidence } \\
\text { interval for Exp (B) }\end{array}$} \\
\hline & B & $\begin{array}{c}\text { Std. } \\
\text { Error }\end{array}$ & Wald & Sig. & Exp(B) & $\begin{array}{c}\text { Lower } \\
\text { Bound }\end{array}$ & $\begin{array}{c}\text { Upper } \\
\text { Bound }\end{array}$ \\
\hline Low vs. Mod Risk & & & & & & & \\
\hline Male & -0.27 & 0.10 & 7.94 & 0.00 & 0.76 & 0.63 & 0.92 \\
\hline White & 0.44 & 0.12 & 13.91 & 0.00 & 1.55 & 1.23 & 1.96 \\
\hline Contact & 0.44 & 0.10 & 19.19 & 0.00 & 1.55 & 1.27 & 1.88 \\
\hline Low vs. High Risk & & & & & & & \\
\hline Male & 0.93 & 0.13 & 50.03 & 0.00 & 2.53 & 1.96 & 3.27 \\
\hline White & 1.47 & 0.19 & 57.44 & 0.00 & 4.35 & 2.98 & 6.37 \\
\hline Contact & 1.14 & 0.15 & 57.59 & 0.00 & 3.11 & 2.32 & 4.18 \\
\hline Mod vs. High Risk & & & & & & & \\
\hline Male & 1.20 & 0.12 & 103.88 & 0.00 & 3.31 & 2.63 & 4.17 \\
\hline White & 1.03 & 0.19 & 30.59 & 0.00 & 2.80 & 1.95 & 4.04 \\
\hline Contact & 0.70 & 0.14 & 24.63 & 0.00 & 2.01 & 1.53 & 2.65 \\
\hline
\end{tabular}

\section{Results of Multinomial Logistic Regression Analyses}

\section{Gender}

We found that male students were less likely than females to be in the Moderate Risk vs the Low Risk cluster $(\mathrm{OR}=.76)$. Males were more likely to be in the High Risk vs the Low risk Cluster than females $(\mathrm{OR}=2.53)$. And males were more likely than females to be in the high risk group than the Moderate Risk cluster $(\mathrm{OR}=3.11)$.

\section{Race}

We found that white students were more likely than minority students to be in the Moderate Risk versus Low Risk $(\mathrm{OR}=1.55)$; Whites were more likely to be in the High Risk than Low Risk (OR 4.35); and more likely to be in high risk versus Moderate Risk $(\mathrm{OR}=2.80)$.

\section{Type of Sport}

Contact student-athletes are more likely than non-contact to be in moderate vs Low Risk $(\mathrm{OR}=1.55)$. Contact students were more likely to be in High versus Low (OR = 3.11); and contact student-athletes were and to be in High risk versus Moderate Risk (OR = 2.01). 


\section{Discussion}

Results suggest that males are more likely than females to be in the high-risk drinking group. This is consistent with the literature (Mays, DePadilla, Thompson, Kushner, \& Windle, 2014; Wilsnack, Wilsnack, Kirstjanson, Vogeltanz-Holm, $\&$ Gmel, 2009) which states that drinking per se and high-volume drinking are consistently more prevalent among men than women. Males and females are equally likely to be in the low risk drinking group. Student-athletes who identify as white are more likely than their non-white counterparts to be in the moderate and highrisk drinking groups. This is consistent with a prior cluster study (Klima, Skinner, Haggerty, Crutchfield, \& Catalano, 2014) in which groups followed well-established race differences, with Whites clustering into frequent drinking groups more than Blacks, and Blacks clustering into non-heavy drinking groups more than Whites. Additionally, student-athletes who play high-contact sports, as defined by the NCAA, are more likely to be in the high-risk drinking group versus moderate risk or low risk. This is a unique finding as no previous research has investigated drinking habits of student-athletes based on the level of contact in the sport they play. For the utility of developing effective interventions, either in face-to-face settings or web-based, this is an important finding and suggests that intervention be tailored and personalized to the individual based on port-type participation.

Overall, these findings suggest that important consideration ought to be given when developing interventions or working closely with collegiate student-athletes. For example, strategies to specifically target white males who play contact sports may be a potentially efficacious strategy. Although non-white females who play low-contact sports tend to be the lowest risk users, it is likely they will still benefit from intervention that may be more personalized to them. For example, rather than focus on the risks of binge or high-risk drinking, they may benefit more from programming that focuses on bystander intervention strategies.

These findings are significant to sport social workers who create and/or provide interventions to student-athletes. If the research shows that white males who play contact sports are at highest risk for alcohol use, clinicians can use that information to tailor their work to focus on the unique needs of that population. Conversely, if non-White females who play low-contact sports are at lowest risk for alcohol use, it may be more important for sport social workers to educate that group about supporting their peers and the bystander effect. Social workers are experts in linking clients with various service providers, streamlining the flow of communication between all involved (Dean \& Rowan, 2014). They can advocate for individual student-athlete's needs, and for the needs of an entire team or athletic program. As such, it is important for sport social workers to be aware of the research surrounding risky drinking behaviors, along with other vulnerabilities that often go unaddressed. 


\section{Limitations}

There are two limitations to note within this study. The first limitation is related to the self-report nature of the data. However, despite this limitation self-report data remain a reliable and valid approach to measure alcohol-related outcomes (Del Boca $\&$ Darkes, 2003). The second limitation of this study is the lack of a behavioral measure of alcohol use. Due to the data for this study being cross-sectional in nature, the inclusion of alcohol use behaviors would not have produced interpretable and more importantly, meaningful results.

\section{References}

Allison, D. B. (2006) Microarray data analysis: from disarray to consolidation and consensus. Nature Review Genetics, 7, 55-65

Arbelaitz, O., Gurrutxaga, I., Muguerza, J., Pérez, J. M., \& Perona, I. (2013)An extensive comparative study of cluster validity indices. Pattern Recognition, 46, 1, 243-256. https:// doi.org/10.1016/j.patcog.2012.07.021

Autti, T., Sipila, L., Autti, H., \& Salonen, O. (1997) Brain lesions in players of contact sports. The Lancet, 349, 9059, 1144. Retrieved from https://login.libproxy.uncg.edu/ login?url=http://search.proquest.com/docview/199058870?accountid=14604

Benton, S. L., Schmidt, J. L., Newton, F. B., Shin, K., Benton, S. A., \& Newton, D. W. (2004) College student protective strategies and drinking consequences. Journal of Studies on Alcohol, 65, 1, 115-121

Bradizza, C. M., Reifman, A., \& Barnes, G. M. (1999) Social and coping reasons for drinking: predicting alcohol misuse in adolescents. Journal on Studies of Alcohol, 60, 4, 491-499

Brenner, J. W., Metz, S. M., \& Brenner, C. J. (2009) Campus involvement, perceived campus connection, and alcohol use in college athletes. Journal of Drug Education, 39, 3, 303-320

Brenner, J., \& Swanik, K. (2007) High-risk drinking characteristics in collegiate athletes. Journal of American College Health, 56, 3, 267-272

Brooks-Russell, A., Simons-Morton, B., Haynie, D., Farhat, T., \& Wang, J. (2014) Longitudinal relationship between drinking with peers, descriptive norms, and adolescent alcohol use. Prevention Science, 15, 4, 497-505

Brown, T. L., Parks, G. S., Zimmerman, R. S., \& Phillips, C. M. (2001) The role of religion in predicting adolescent alcohol use and problem drinking. Journal of Studies on Alcohol, 62, 5, 696-705

Carey, K., Scott-Shelton, L.A., Elliot, J.C., Bolles, J.R., \& Carey, M.P. (2009) Computerdelivered interventions to reduce college student drinking: A meta-analysis. Addiction, 104, 1807-1819

Dean, C., \& Rowan, D. (2014) The social workers' role in serving vulnerable athletes. Journal of Social Work Practice, 28, 2, 219-227 
Delva, J., Smith, M. P., Howell, R. L., Harrison, D. F., Wilke, D., \& Jackson, D. L. (2004) A study of the relationship between protective behaviors and drinking consequences among undergraduate college students. Journal of American College Health, 53, 1, 19-26

Denny, K. G., \& Steiner, H. (2009) External and internal factors influencing happiness in elite collegiate athletes. Child Psychiatry and Human Development, 40, 1, 55-72

Doumas, D. M., Turrisi, R., Coll, K. M., \& Haralson, K. (2007) High-risk drinking in college athletes and nonathletes across the academic year. Journal of College Counseling, 10, 2, 163-174

Elliott, J.C., Carey, K.B., \& Bolles, J.R. (2008) Computer-based interventions for college drinking: A qualitative review. Addictive Behaviors, 33, 994-1005

Fearnow-Kenney, M., Wyrick, D. L., Milroy, J. J., Reifsteck, E., Kelly, S.E., Day, T.F. (2016) The Effect of a Web-Based Alcohol Prevention Program on Social Norms, Expectancies, and Intentions to Prevent Harm among College Student-Athletes. The Sport Psychologist. $30,2), 113-122$

Finch, H. (2005) Comparison of distance measures in cluster analysis with dichotomous data. Journal of Data Science, 3, 85-100

Finlay, A. K., White, H. R., Mun, E., Cronley, C. C., \& Lee, C. (2012) Racial differences in trajectories of heavy drinking and regular marijuana use from ages 13 to 24 among African American and White males. Drug and Alcohol Dependence, 121, 1, 118-123

Gastil, J. (2000) Thinking, drinking, and driving: Application of theory of reasoned action to DWI prevention. Journal of Applied Social Psychology, 30, 11, 2217-2232

Green, K., Hartmann, D., \& Nelson, T. (2014) Binge drinking and sports participation in college: Patterns among athletes and former athletes. International Journal of the Sociology of Sport, 49, 417-434

Grimm, L. G., \& Yarnold, P. R. (2000) Reading and understanding more multivariate statistics. Washington, DC: American Psychological Association

Grossbard, J. R., Geisner, I. M., Neighbors, C., Kilmer, J. R, \& Larimer, M. E. (2007) Are drinking games sports? College athlete drinking game participation and alcohol-related problems. Journal of Studies on Alcohol and Drugs, 68, 97-105

Haines, M. P., Barker, G., \& Rice, R. M. (2006) The personal protective behaviors of college student drinkers: Evidence of indigenous protective norms. Journal of American College Health, 55, 2, 69-76

Huang, J., Jacobs, D., \& Derevensky, J. (2010) Sexual risk-taking behaviors, gambling, and heavy drinking among U. S. college athletes. Archives of Sexual Behavior, 39, 3, 706-713

Husic, B. E., McKiernan, K. A., Wayment-Steele, H. K., Sultan, M. M., \& Pande, V. S. (2018) A minimum variance clustering approach produces rubust and interpretable coarse-grained models. Journal of Chemical Theory and Computation, 14, 2, 1071-1082

Hustad, J.T.P., Barnett, N.P., Borsari, B., \& Jackson, K.M. (2010) Web-based alcohol prevention for incoming college students: A randomized controlled trial. Addictive Behaviors, 35,183-189

Jackson, K. M. (2008) Heavy episodic drinking: determining the predictive utility of five or more drinks. Psychology of Addictive Behaviors, 22, 1, 68-77 
Johnston, L. D., O’Malley, P. M., Bachman, J. G., \& Schulenberg, J E. (2010) Monitoring the future national survey results on drug use, 1975-2009: Volume I, Secondary school students (NIH Publication No. 10-7584) Bethesda, MD: National Institute on Drug Abuse. Retrieved from http://monitoringthefuture.org/pubs/monographs/voll_2009.pdf

Klima, T., Skinner, M. L., Haggerty, K. P., Crutchfield, R. D., \& Catalano, R. F. (2014) Exploring heavy drinking patterns among black and white young adults. Journal of Studies on Alcohol and Drugs, 75, 5, 839-849

Kwan, M., Bobko, S., Faulkner, G., Donnelly, P., \& Cairney, J. (2014) Sport participation and alcohol and illicit drug use in adolescents and young adults: A systematic review of longitudinal studies. Addictive Behaviors, 39, 3, 497-506

LaBrie, J. W., Lac, A., Kenney, S. R., \& Mirza, T. (2011) Protective behavioral strategies mediate the effect of drinking motives on alcohol use among heavy drinking college students: Gender and race differences. Addictive Behaviors, 36, 354-361

Lewis, M. A., Rees, M., Logan, D. E., Kaysen, D. L., \& Kilmer, J. R. (2011) Use of drinking protective behavioral strategies in association to sex-related alcohol negative consequences: The mediating role of alcohol consumption. Psychology of Addictive Behaviors, 24, 2, 229-238

Linden-Carmichael, A. N., Vasilenko, S. A., Lanza, S. T., \& Maggs, J. L. (2017) Highintensity drinking versus heavy episodic drinking: Prevalence rates and relative odds of alcohol use disorder across adulthood. Alcoholism: Clinical and Experimental Research, 41, 10, 1754-1759

Lisha, N. E. and Sussman, S. (2010) Relationship of high school and college sports participation with alcohol, tobacco, and illicit drug use: A review. Addictive Behaviors, 35, 5, 399-407

MacKinnon, D. P. (1994) Analysis of Mediating Variables in Prevention and Intervention Research. In Scientific Methods for Prevention Intervention Research: NIDA Research Monograph 139, DHHS Pub. 94-3631, ed A Cazares, LA Beatty, pp. 127-153. Washington, DC: U.S. Department of Health and Human Sciences

Martens, M. P. (2017) Alcohol abuse and drug use in sport and performance. Oxford Research Encyclopedias: Psychology. DOI: 10.1093/acrefore/9780190236557.013.168

Masyn, K. (2013) Latent Class Analysis and Finite Mixture modeling. In T. Little (Ed.), The Oxford Handbook of Quantitative Methods in Psychology: Vol. 2: Statistical Analysis (Vol. 2, pp. 1-44) New Your: Oxford

Mays, D., DePadilla, L., Thompson, N. J., Kushner, H. I., \& Windle, M. (2014) Sports participation and problem alcohol use. American Journal of Preventative Medicine, 38, 5 , 491-498

Milligan, G. W., \& Cooper, M. C. (1985) An examination of procedures for determining the number of clusters in a data set. Psychometrika, 50, 2, 159-179

Namisango, E., Harding, R., Katabira, E. T., Siegert, R. J., Powell, R. A., Atuhaire, L., Moens, K., \& Taylor, S. (2015) A novel symptom cluster analysis among ambulatory HIV/AIDS patients in Uganda. AIDS Care, 27, 8, 954-963

National Collegiate Athletic Association (NCAA) (2014) Mind, Body and Sport Understanding 
and Supporting Student-Athlete Mental Wellness. NCAA: Indianapolis

National Collegiate Athletic Association (NCAA) (2018) NCAA National Study on Substance Use Habits of College Student-Athletes: Final report

National Institute on Alcohol Abuse and Alcoholism (2015) College fact sheet. College drinking. Retrieved from http://pubs.niaaa.nih.gov/publications.CollegeFactSheet/ CollegeFactSheet.pdf

Nattiv, A., \& Puffer, J. (1991) Lifestyles and health risks of collegiate athletes. The Journal of Family Practice, 33, 6, 585-590

Naylor, A. H., Gardner, D., \& Zaichkowsky, L. (2001) Drug use patterns among high school athletes and nonathletes. Adolescence, 36, 144, 627-639

Nelson, T. F., \& Wechsler, H. (2001) Alcohol and college athletes. Medicine and Science in Sports and Exercise, 33, 1, 43-47

O'Brien, C. P., \& Lyons, F. (2000) Alcohol and the athlete. Sports Medicine, 29, 5, 295-300

Paschall, M. J., \& Flewelling, R. L. (2002) Postsecondary education and heavy drinking by young adults: the moderating effect of race. Journal of Studies on Alcohol, 63, 4, 447-455

Romesburg, C. H. (2004) Cluster analysis for researchers. Raleigh, NC: Lulu Press

Rooke, S., Thorsteinsson, E., Karpin, A., Copeland, J., Allsop, D. (2010) Computer-delivered interventions for alcohol and tobacco use: a meta-analysis. Addiction, 105, 8, 1381-90

Sabo, D., Miller, K. E., Melnick, M. J., Farrell, M. P., \& Barnes, G. M. (2002) Athletic participation and the health risks of adolescent males: A national study. International Journal of Men's Health, 1, 173-193

Substance Abuse and Mental Health Services Administration (SAMHSA) (2014) National Survey on Drug Use and Health. SAMHSA: Rockville, MD

Samuolis, J., Loser, A., \& Tyrrell, A. (2018) Protective behavioral strategies and alcohol use outcomes among college students: The moderating effects of negative affect. Journal of Drug Education, 48, 1-2, 54-66.

Shirreffs, S. M., \& Maughan, R. J. (2006) The effect of alcohol on athletic performance. Current Sports Medicine Reports, 5, 192-196

Terlecki, M. A., Buckner, J. D., Larimer, M. E., \& Copeland, A. L. (2015) Randomized controlled trial of brief alcohol screening and intervention for college students for heavydrinking mandated and volunteer undergraduates: 12-month outcomes. Psychology of Addictive Behaviors, 29, 1, 2-16

Thombs, D. L., \& Hamilton, M. (2002) Effects of a social norm feedback campaign on the drinking norms and behavior of Division I student-athletes. Journal of Drug Education, 3, 227-244

Turrisi, R., Mallett, K. A., Mastroleo, N. R., \& Larimer, M. E. (2010) Heavy drinking in college students: who is at risk and what is being done about it? The Journal of General Psychology, 133, 4, 401-420

Venne, S., Laguna, P., Walk, S., \& Ravizza, K. (2006) Optimism levels among collegiate athletes and non-athletes. International Journal of Sport and Exercise Psychology, 4, 2, 182195 
Walters, S. T., Roudsari, B. S., Valder, A. M., \& Harris, T. R. (2007) Correlates of protective behavior utilization among heavy-drinking college students. Addictive Behaviors, 32, 2633-2644

Ward, J. H. (1963) Hierarchical grouping to optimize an objective function. Journal of the American Statistical Association, 58, 236-244

Wechsler, H., \& Nelson, T. F. (2008) What we have learned from the Harvard School of Public Health College Alcohol Study: Focusing attention on college student alcohol consumption and the environmental conditions that promote it. Journal of Studies on Alcohol and Drugs, 69, 4, 481-490

Wiers, R. W., \& Kummeling, R. H. (2004) An experimental test of an alcohol expectancy challenge in mixed gender groups of young heavy drinkers. Addictive Behaviors, 29, 1, 215-220

Wilsnack, R. W., Wilsnack, S. C., Kristjanson, A. F., Vogeltanz-Holm, N. D., \& Gmel, G. (2009) Gender and alcohol consumption: Patterns from the multinational Genacis Project. Addiction, 104, 9, 1487-1500

Yusko, D. A., Buckman, J. F., White, H. R., \& Pandina, R. J. (2008) Risk for excessive alcohol use and drinking-related problems in college student athletes. Addictive Behaviors, 33, $12,1546-1556$ 